\title{
Diagnóstico prenatal de tumor de células de la granulosa de tipo juvenil
}

\author{
Isabel González B. ${ }^{1}$, Eva Lucía Tejero C. ${ }^{2}$, Isabel Marquina I. ${ }^{3}$, Diego Lerma $P^{4}$, Beatriz \\ Rojas PE. ${ }^{1}$, Pilar Pérez . $^{4}$ \\ ${ }^{1}$ Servicio de Ginecología y Obstetricia. Hospital de Barbastro, Huesca. ${ }^{2}$ Servicio de Ginecología y Obstetricia, Unidad \\ de Medicina Materno-Fetal, Hospital Universitario Miguel Servet, Zaragoza. ${ }^{3}$ Servicio de Anatomía Patológica, Hospital \\ Universitario Miguel Servet, Zaragoza. ${ }^{4}$ Servicio de Ginecología y Obstetricia, Unidad de Diagnóstico Prenatal, Hospital \\ Universitario Miguel Servet, Zaragoza. España.
}

\section{RESUMEN}

Presentamos un caso clínico de diagnóstico prenatal de una masa testicular. Tras el nacimiento, se realizó la exéresis del tumor y el análisis anatomopatológico determinó que se trataba de un tumor de células de la granulosa juvenil. Los tumores testiculares son raros y deben considerarse en el diagnóstico diferencial de las masas escrotales en los neonatos. El tumor de células de la granulosa juvenil es una entidad clínicopatológica poco frecuente, que representa el $5 \%$ de los tumores testiculares prepuberales. Se considera una neoplasia benigna y la orquiectomía es una técnica quirúrgica curativa.

\section{PALABRAS CLAVE: Neoplasia testicular, tumor de células de la granulosa juvenil, alfa-fetoproteína, diagnóstico prenatal}

\section{SUMMARY}

We report a case of a prenatally diagnosed testis tumor. After delivery, it was decided to perform right radical orchiectomy which was subsequently diagnosed as a juvenile granulosa cell tumor. Neonatal testicular tumors are rare and should be considered in the differential diagnosis of newborn scrotal masses. Juvenile granulosa cell tumor is a rare benign neoplasm of the testicular stroma that accounts for $5 \%$ of all prepuberal testis tumors. As a benign neoplasm, orchiectomy is sufficient for treatment.

\section{KEY WORDS: Testis tumor, juvenile granulosa cell tumor, alpha-fetoprotein, prenatal diagnosis}

\section{INTRODUCCIÓN}

Los tumores testiculares prepuberales son raros y suponen el $1 \%$ de todos los tumores pediátricos sólidos (1) El tumor de células de la granulosa es una neoplasia benigna. Aunque es raro, es la más común de las neoplasias del estroma gonadal en la infancia ( $15 \%$ de los tumores de este grupo). Se presenta como una masa escrotal indolora. La exploración ecográfica muestra un tumor circunscrito de apariencia multiquística. Únicamente se han publicado tres casos más de diagnóstico prenatal (2-4).

\section{Caso clínico}

Gestante de 39 años, cuartigesta, con tres abortos previos. Sin antecedentes familiares ni personales de interés y no declara el uso de drogas ni medicamentos fuera de los habituales, ni durante la gestación, ni en el periodo preconcepcional. 
Con control gestacional normal y ecografías previas sin hallazgos patológicos, acude a realizar la ecografía de tercer trimestre a las 35 semanas (establecida por fecha de última regla). Durante la exploración, realizada con un ecógrafo Voluson E8 (General Electrics, Alemania), se observó un feto vivo, sexo masculino, con peso fetal estimado de 2435 gramos (percentil 50 para su edad gestacio- nal), líquido amniótico en cuantía normal y placenta normoinserta de localización posterior. La valoración sistemática de la anatomía fetal mostró un testículo izquierdo normal de $13 \mathrm{~mm}$ y un testículo derecho de $24 \mathrm{~mm}$ con múltiples formaciones anecoicas de aspecto displásico (Figura 1 y 2). Resto de la exploración ecográfica sin hallazgos patológicos.

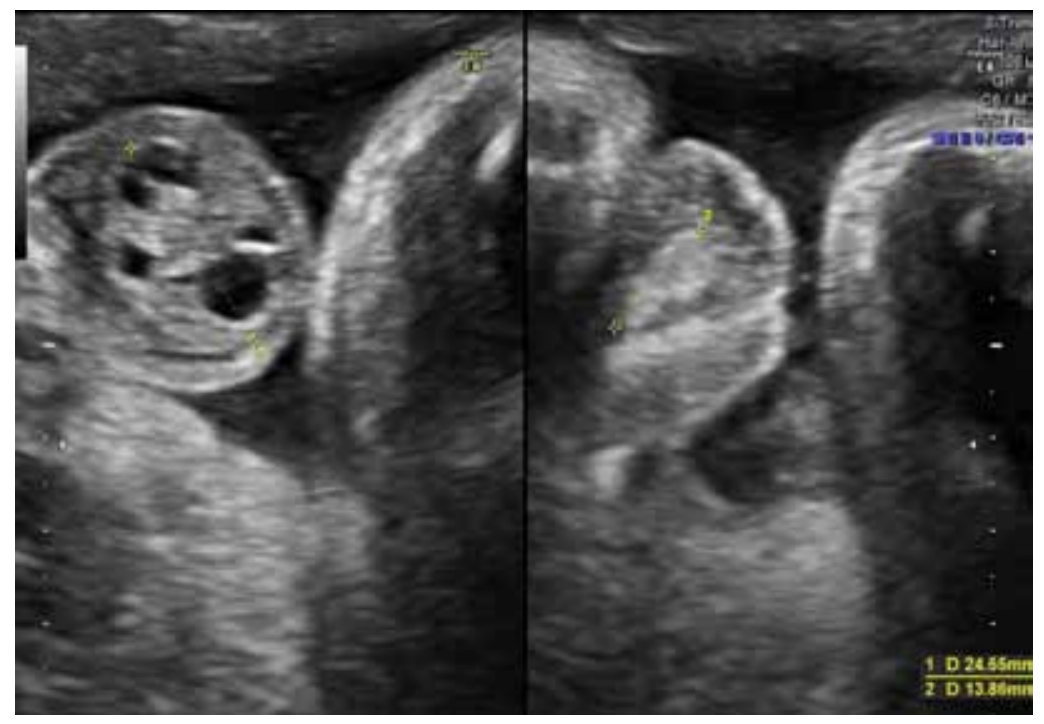

Figura 1. Testículo izquierdo normal de 13,86 mm (izquierda) y testículo derecho aumentado de tamaño de 24,65 $\mathrm{mm}$ (derecha).

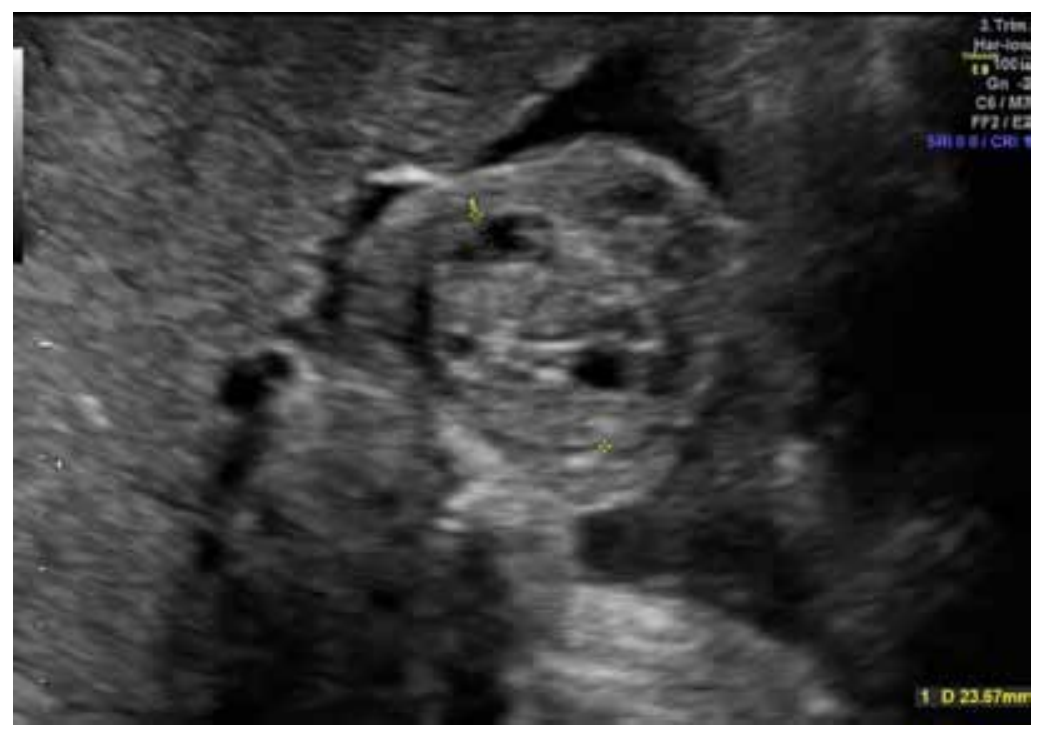

Figura 2. Testículo derecho con múltiples formaciones anecoicas de aspecto displásico. 
A las $39^{+2}$ semanas parto eutócico con profilaxis antibiótica completa por cultivo vagino-rectal positivo para Streptococcus agalactiae. Recién nacido masculino de 2910 gramos, Apgar 9-10. EI aspecto fenotípico era normal, sin características dismórficas. En la primera exploración postnatal los genitales externos masculinos eran aparentemente normales con testes en bolsa escrotal, pero macroscópicamente el testículo derecho estaba aumentado de tamaño $(30 \times 20 \mathrm{~mm})$ con consistencia heterogénea, tumefacto y con coloración normal. Testículo izquierdo normal. No se palpaban hernias inguinales ni adenopatías. Tras el nacimiento el recién nacido ingresó en la Unidad de Neonatos por tumoración testicular derecha a estudio. La ecografía escrotal mostró un testículo izquierdo alojado en bolsa escrotal, de tamaño y ecoestructura normal, de $9 \times 6 \mathrm{~mm}$ con vascularización normal por ecodoppler. El testículo derecho, presenta masa de 24 x $17 \mathrm{~mm}$ de naturaleza sólida con múltiples áreas líquidas/quísticas en su interior y aumento de la vascularización por eco-doppler. Se establecieron los tumores testiculares como diagnóstico diferencial: tumor juvenil de células de la granulosa, tumor del estroma gonadal, teratoma quístico y displasia quística testicular.

Se realizaron otras pruebas complementarias con ecografía abdominal, radiografía de tórax, hemograma, bioquímica, hemostasia, grupo sanguíneo y marcadores tumorales. Todas las pruebas fueron normales salvo los marcadores tumorales con una elevación de la alfafetoproteína (AFP) de $45.836,5 \mathrm{ng} / \mathrm{ml}$ y de la $\beta-H C G$ de $59,61 \mathrm{mUl} / \mathrm{ml}$.

A las 24 horas de vida se decidió realizar una inguinotomía derecha con extirpación del cordón espermático y masa tumoral testicular derecha de consistencia dura y sin identificarse estructura testicular normal. El estudio anatomopatológico demostró una pieza quirúrgica ovoidea de 7 gramos compuesta por testículo de $2,5 \mathrm{~cm}$ de diámetro máximo y cordón espermático de $4 \mathrm{~cm}$ de longitud. Al corte se observa una tumoración redondeada multiquística con tractos sólidos entre los quistes, blanquecino-amarillenta, con contenido fluido transparente.

En el estudio histológico de la tumoración se identifica un componente sólido acompañado por múltiples quistes con contenido basófilo que se encuentran revestidos por células grandes predominantemente redondeadas, algunas vacuoladas, con núcleo redondeado, alguno de ellos con nucleolo. También se identifican otras células más pequeñas, con citoplasma escaso y sin atipia citológica. Se observan algunas figuras de mitosis (Figura 3).

En el estudio inmunohistoquímico se observa que las células tumorales expresan vimentina,

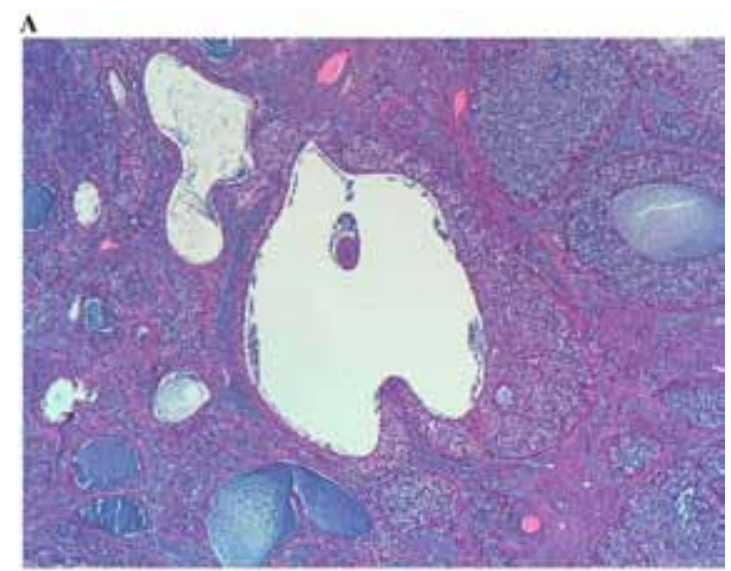

B

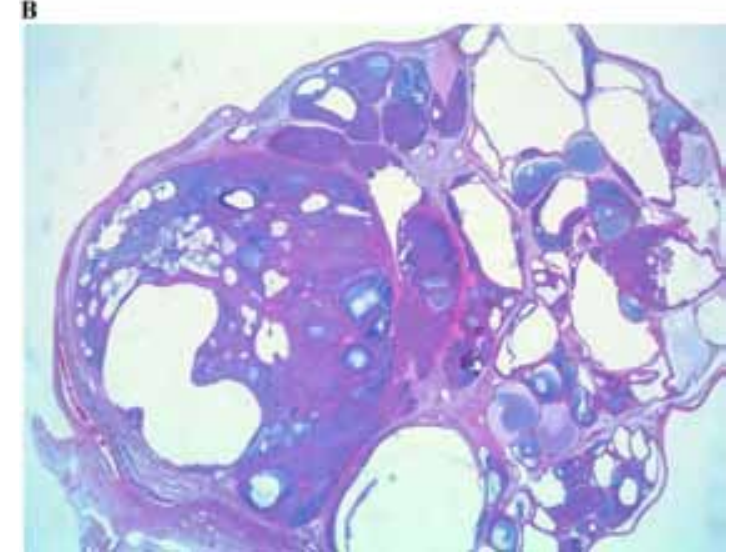

Figura $3 A$ y $B$. Tinción hematoxilina-eosina. Se observa componente sólido con múltiples quistes con contenido basófilo revestidos por células grandes predominantemente redondeadas y algunas vacuoladas.

alfa-inhibina, CD99, S100 y citoqueratina AE1/ AE3. No se evidencia expresión de alfafetoproteína, PLAP, D2-40, Glypican-3, CD117 ni CD30. El índice proliferativo con Ki67 es del $20 \%$. Con todos estos datos histológicos e inmunohistoquímicos el diagnóstico fue de tumor de células de la granulosa de tipo juvenil (Figura 4).

No hubo complicaciones intra ni postoperatorias. La evolución fue satisfactoria y ante el buen estado general se dio de alta con su madre a las 36 horas de vida. Actualmente, tras dos meses poscirugía, el paciente se encuentra sano. Acude a revisiones periódicas evidenciándose un descenso progresivo de la AFP. 


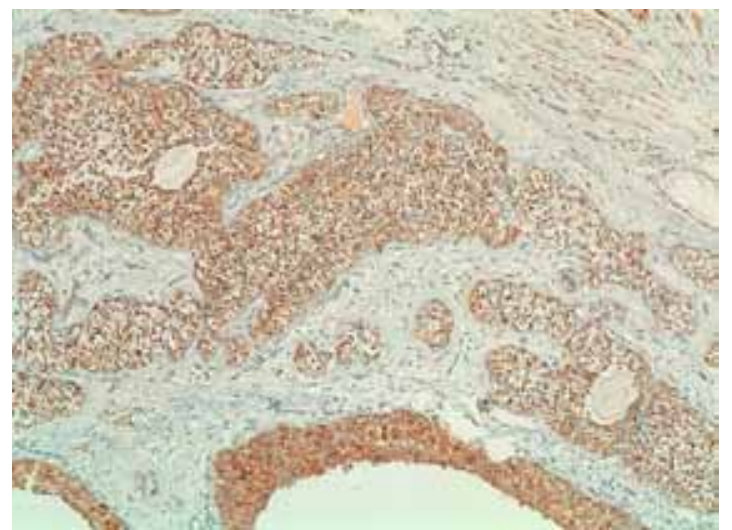

Figura 4. Reactividad inmunohistoquímica frente a alfa inhibina.

\section{DISCUSIÓN}

Los tumores de las células de la granulosa son tumores del estroma del cordón gonadal, que ocurren en el ovario y en el testículo. Representan el $10-20 \%$ de todos los tumores del estroma del cordón gonadal. Estos tumores pueden ocurrir en formas juveniles y adultas. La forma juvenil es una variante rara, representando menos del $5 \%$ de todos los tumores de células de la granulosa. En varones, los tumores de células de la granulosa representan la forma más frecuente de neoplasia congénita testicular y la mayoría ocurren en el periodo perinatal. Suelen presentarse como masas abdominales o escrotales, más frecuentemente afectando al testículo izquierdo. Aproximadamente el $20 \%$ de los pacientes tienen genitales externos ambiguos. Con frecuencia están asociados a anomalías cromosómicas (4-6). A diferencia de los tumores localizados en el ovario que no han sido reportadas disfunciones endocrinas secundarias (7).

Ecográficamente, la imagen típica es la de una masa multiquística en el parénquima testicular. Clínicamente, la evolución del tumor es benigna y la orquiectomía se ha definido como la técnica quirúrgica curativa (3). La quimioterapia y radioterapia no se contemplan en el tratamiento de este tumor puesto que su comportamiento es no invasivo y en ningún caso se han descrito metástasis (2).

Macroscópicamente es un tumor parcialmente encapsulado cuyo tamaño puede variar de 1 a 6,5 $\mathrm{cm}$ y caracterizado por presentar múltiples áreas quísticas de paredes delgadas rellenas por material mucoideo que en ocasiones puede alternar con áreas sólidas pardo amarillentas, sin presentar necrosis o hemorragia. Histológicamente, la lesión presenta un doble patrón: folicular y sólido. Los folículos son de tamaño variable confiriéndole la apariencia macroscópica quística y rellenos por un material eosinófilo o basófilo, positivo para tinciones de mucinas. Estos folículos están revestidos por un número variable de capas de células de la granulosa (7).

El diagnóstico diferencial de este tumor se establece con otras lesiones quísticas testiculares tales como el teratoma quístico testicular, tumor del saco vitelino, displasia testicular quística, linfangioma quístico o la transformación quística del testículo tras la torsión del cordón espermático, siendo de vital importancia el correcto diagnóstico de cada uno de ellos pues presentan pronósticos y conductas terapéuticas muy distintas $(8,9)$.

En la literatura existen diversos estudios, aunque no muy abundantes, en los que se recogen diferentes diagnósticos de tumores testiculares: en 2001, Siu y cols (10) publicaron el diagnóstico ecográfico en semana 30 de una masa intrabadominal, cuyo aspecto ecográfico recordaba al de un quiste dermoide ovárico propio de la mujer en edad adulta, cuyo estudio anatomopatológico posterior a la orquiectomía fue de teratoma con componentes maduros e inmaduros. En 2008, Peterson y Skoog (3) publicaron un caso de una masa quística intratesticular izquierda diagnosticada en ecografía a la semana 35; tras la orquiectomía, el resultado anatomopatológico fue de tumor juvenil de células de la granulosa. En 2012, Bulotta y cols (2) publicaron también el diagnóstico ecográfico en semana 36 de una masa multiquística testicular izquierda con el mismo resultado anatomopatólogico.

\section{CONCLUSIÓN}

Los tumores testiculares son raros pero deben tenerse en cuenta en el diagnóstico diferencial de las masas escrotales en los neonatos, debiéndose realizar siempre una exploración sistemática de los genitales. Además, hay que considerar la posibilidad de su diagnóstico ecográfico prenatal.

\section{REFERENCIAS}

1. Bujons A, Caffaratti J, Pascual M, Angerri O, Garat JM y Villavicencio $\mathrm{H}$. Tumores testiculares en la infancia. Actas Urológicas Españolas 2011;35 (2):93-98.

2. Bulotta AL, Molinaro F, Angotti R, Ferrara F, Di Maggio $G$, Bindi $E$, Messina $M$. Juvenile granulosa cell tumor of the testis: prenatal diagnosis and escrotal approach. Ital J Pediatr 2012;38:67.

3. Peterson Ch, Skoog S. Prenatal diagnosis of juvenile granulosa cell tumor of the testis. J Pediatr Urol 2008;4:472-4.

4. Illescas T, Ibba RM, Zoppi MA, luculano A, Contu $R$, Monni G. Prenatal ultrasound diagnosis of a fetal testis granulosa cell tumour. J Obstet Gynaecol 2014;34(1):96-7.

5. Zugor V, Labanaris AP, Witt J, Seidler A, Weingärtner K, Schott GE. Congenital juvenile granulosa 
cell tumor of the testis in newborns. Anticancer Res 2010;30(5):1731-4.

6. Leylek, AM, Kane, Robert A. Juvenile granulosa cell tumor of the testis. Ultrasound Quarterly 2014;30(3):219-20.

7. Tapia EO, Delgado SMC, Bellolio JE, Villaseca HM. Tumor de células de la granulosa del testículo tipo juvenil: reporte de un caso y revisión de la literatura. Int J Morphol 2010;28(2):477-82.

8. Barroca H, Gil-da-Costa MJ, Mariz C. Testicular juvenile granulosa cell tumor: a case report. Acta Cytol 2007;51(4):634-6.

9. Janda GM, Najdzionek JS, Kozielski R, Greenfield $\mathrm{SP}$, Williot PE. Early prenatal detection of an intraabdominal cryptorchid testicular teratoma. Urology 2014;83 (1):214-6.

10. Siu SS, Leung TN, Leung TY, Ng SW, Yeung CK, Lau TK. Prenatal diagnosis of intra-abdominal mature testicular teratoma. J Ultrasound Med 2001;20(11):125760. 